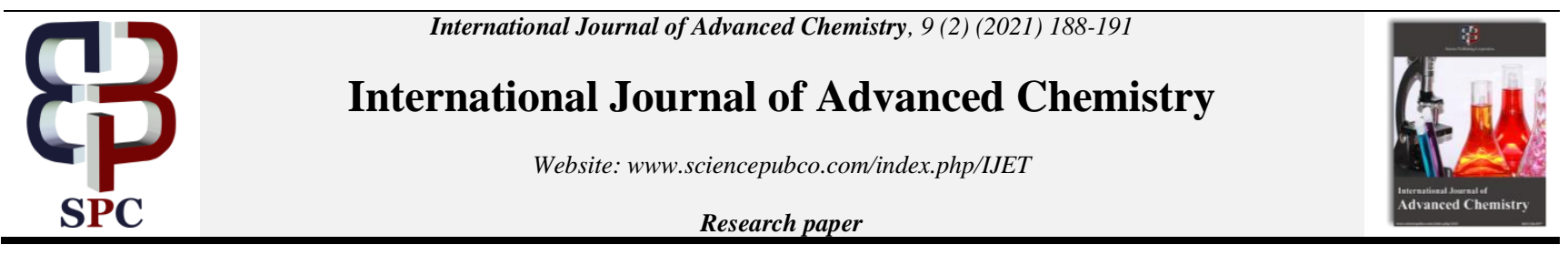

\title{
Development and characterization of catalyst materials from magnetic sand, Crotalaria pallida and kaolin
}

\author{
Shalbugau K. W. ${ }^{1}$, Dass P. M. ${ }^{1}$, Iji M. ${ }^{2}$, Nkafamiya I. I. ${ }^{1}$, Maitera O. N. ${ }^{1}$ \\ ${ }^{1}$ Department of Chemistry, Modibbo Adama University of Technology, Yola \\ ${ }^{2}$ Department of Chemistry, Abubakar Tafawa Balewa University, Bauchi \\ *Corresponding author E-mail: martinsiji247@gmail.com
}

\begin{abstract}
In this study, magnetic sand and Crotalaria pallida gotten from Adamawa and Bauchi states of Nigeria, respectively, were mixed after treatment, and impregnated with kaolin using a wet impregnation method and the resulting material was characterized using scanning electron microcopy (SEM), X-ray fluorescence (XRF) and X-ray diffraction (XRD). The result of XRF analysis revealed the existence of a number of dopant-like constituents in the sample, which substitute parts of important atoms in the spinel structure, however, not forming individual phases. The SEM micrographs displayed pore structures with high surface area consistent with effective catalyst materials. XRD analysis confirmed crystalline phases of the hybrid material showing typical diffraction peaks of kaolinite minerals (A12Si2O9), Muscovite (A112FeSi12K4NaRbH16O48), quartz, Si3O6 Calcite (Ca6C6O18) and Halite (Na4Cl4) and the average crystallite size was determined to be $75.30 \mathrm{~nm}$.
\end{abstract}

Keywords: Catalysts; Impregnation; Kaolin; Material Characterization; Morphology.

\section{Introduction}

Catalysis is a scientific process by which the rate of chemical reactions can be enhanced by small amounts of foreign substances. These foreign substances are called catalysts and do not initiate a reaction; they only accelerates an already thermodynamically feasible reaction without altering the position of the thermodynamic equilibrium [1]. Catalysts account for the production of over $60 \%$ of all chemicals and are used in about $90 \%$ of all chemical processes universally [2, 3]. As reported by a 2002 article examining the effect of catalysis on the economy of the United States of America, "one-third of material gross national product in the United States involves a catalytic process somewhere in the production chain" [4].

Heterogeneous catalysis has been a subject of considerable interest for fundamental studies of chemistry and for practical applications in chemical industries, for a long time [5-7]. Heterogeneous catalysis is also a key technology for the energy and environmental fields, concerning the production of fuels and chemicals and in the clean-up of hazardous, poisonous, or polluting wastes [8]. Heterogeneous catalysts display a number of advantages over their homogeneous counterparts; they are environmentally benign, easy to separate and require simple post treatments. Many chemical reactions such as transesterification reaction can be done using solid acid or base catalyst [14].

One fascinating and perhaps crucial peculiarity of heterogeneous catalysts is the fact that they are adaptable [12], to the extent that the cavity, active site, and binding sites migrate during the process of the reaction to allow for the adsorption and release of the reacting species. As a result, in the development of a designed heterogeneous catalyst, it would be expedient to have total control over the forming of the active site, the environment surrounding the active site, the binding sites and their positions with respect to the active site, and the pathway to access these range of capabilities. Specifically, it is most desirable to have full control from the atomic scale, all the way to tens, and even hundreds of nanometer scale.

Various reactions that are catalyzed by acids and bases in solutions may also be catalyzed by solids having acidic and basic characteristics. In most cases, solid acid catalysts made use of are mixed oxides, zeolites and clays. The fact that they have layered structure, high specific surface area, high cation exchange capacity (CEC), chemical and mechanical stability, Bronsted and Lewis acidity, etc., makes the clays superb materials for adsorption [9]. Two classes of clay mineral can be found in nature with regards to their tetrahedral/octahedral ratio: 1:1 structures and 2:1 structures. Kaolinite has a 1:1 layer structure, first proposed by Pauling [10] with the fundamental unit consisting of a tetrahedral sheet of $\mathrm{SiO} 4$ and an octahedral sheet with $\mathrm{Al}^{3+}$ as the octahedral cation.

Kaolin clay contributes a cheap and richly available alternative able to be utilized in the synthesis and development of mesoporous aluminosilicates and an array of microporous zeolite frameworks [11]. Kaolin clay is an inexpensive and versatile precursor which is found in a large number of geographical locations and has been utilized favourably in the synthesis and development of mesoporous aluminosilicates [13] and many microporous zeolite frameworks [15 - 19]. 


\section{Materials and methods}

\subsection{Catalyst preparation}

Crotalaria pallida plants were obtained around Hildi village in Hong L.G.A of Adamawa state, Nigeria. The plant was dried at room temperature, crushed and carbonized at $600{ }^{\circ} \mathrm{C}$ in an oven, to obtain its ash.

$500 \mathrm{~g}$ each of Magnetic sand and Kaolin were collected from their deposits in Adamawa and Bauchi, respectively.

The catalysts were prepared by established wet impregnation method [20]. $10 \mathrm{~g}$ of kaolin was mixed with $30 \mathrm{ml}$ of distilled water under stirring. A mixture of $10 \mathrm{~g}$ each of Crotalaria pallida ash and magnetic sand was made and added slowly to $20 \mathrm{ml}$ of the mixture slurry of kaolin and stirred continually to obtain a smooth mixture. The water was removed by heating the sample in an oven at $100{ }^{\circ} \mathrm{C}$ for 3 hours. The powder so obtained was calcined at $500{ }^{\circ} \mathrm{C}$ for 5 hours.

\subsection{Catalyst characterization}

\subsubsection{Scanning electron microscopy (SEM)}

The catalyst was examined by the use of a scanning electron microscope (SEM), serial number MVE01570775 and model number 800 07334, manufactured by PRO: X: Phenonm World.

\subsubsection{X-ray fluorescence}

Chemical composition of the catalyst was further done by X-ray florescence by a standard method EDXRF analyzer using monochromatic radiation with K-Alpha1 wavelength $1.540598 \AA$ and a linear analysis technique.

A Tema vibrating mill was used to prepare the catalyst for XRF analysis by crushing the catalyst. The material was sieved using a 63 microns sieve to give a uniform particle size. $10 \mathrm{~g}$ of the powdered samples was dried in an oven at $110^{\circ} \mathrm{C}$ for 24 hours before major elemental analysis in the computerized XRF and the condition for trace elemental analysis set to give the result in elemental form.

\subsubsection{X-ray diffractometer (XRD)}

Phase identification and crystallinity study of the catalyst was done using X-ray diffractometer (XRD) on an EMPYREAN diffractometer system. The material was finely ground and homogenized. Average bulk composition was determined and $1 \mathrm{~g}$ of the powdered sample was compressed in the sample holder before being placed in the XRD cabinet.

XRD result data was obtained between $4^{\circ}$ and $75^{\circ} 2 \theta$ at tube current of $40 \mathrm{~mA}$ and $45 \mathrm{VA}$ tension. Fixed Divergent Slit size of $1^{\circ}$ was used and the goinometer radius was $240 \mathrm{~mm}$.

\section{Result and discussion}

\subsection{Scanning electron microscopy}

The morphological characteristics of the solid particles as observed by Scanning Electron Microscopy (SEM) depicted in Figure 1 shows a layered and multi-dimensional porous structure having small basal spacing. The layers were clearly kept apart, giving rise to large pore structures as shown in the micrograph (Figure 1).

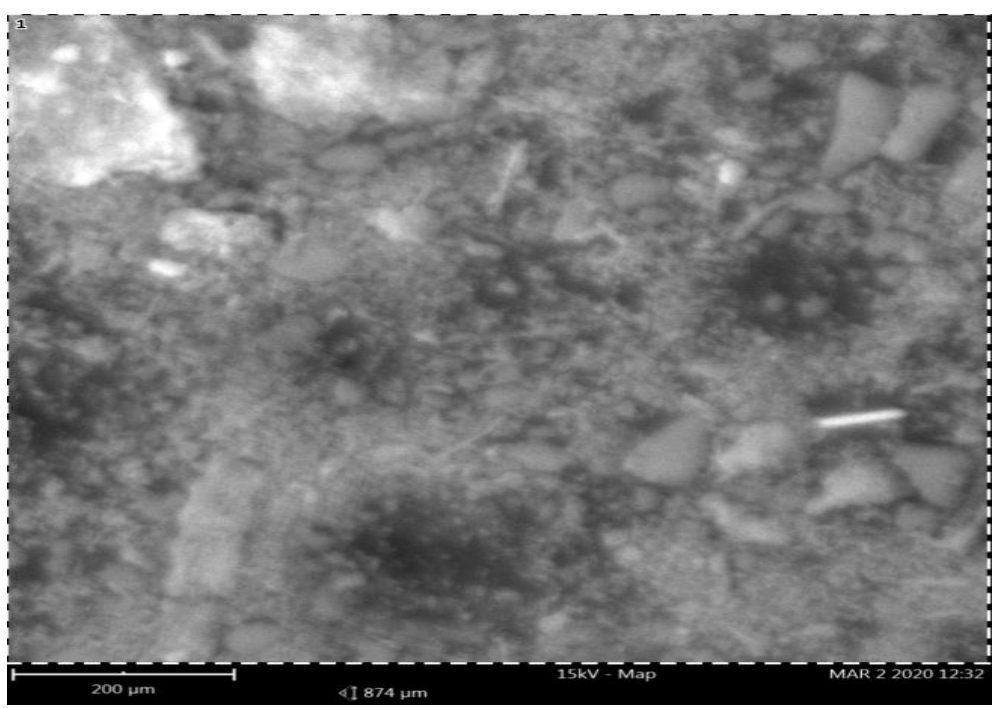

Fig. 1: SEM Micrograph of Magnetic Sand/Crotalaria pallida/Kaolin Catalyst Material

\subsection{X-ray fluorescence analysis}

XRF data revealed the elemental compositions of the synthesized catalyst materials. Results of XRF analysis of the Magnetic sand/Crotalaria pallida/Kaolin materials are presented in Table 1. It can be seen that Fe is the major elemental constituent with $12.696 \%$ followed by $\mathrm{K}$ and $\mathrm{Si}$ with $10.964 \%$ and $10.940 \%$ respectively. $\mathrm{Ca}$ and $\mathrm{Al}$ had percentages of $9.305 \%$ and $6.105 \%$ respectively while $\mathrm{Mg}$ was present in $3.79 \%$ by composition. Other elements were present in minute quantity as shown in Table 1 . The presence of those minute 
elements act as impurities, altering the catalytic behavior of the material positively, acting as dopants substituting some part of essential elemental atoms in the structure without forming other individual phases of their own.

Table 1: XRF Result Showing Elemental Composition of Magnetic Sand/Crotalaria pallida/Kaolin Catalyst Material

\begin{tabular}{|c|c|c|}
\hline S/No & Elements & Concenteration (\%) \\
\hline 1 & $\mathrm{Fe}$ & 12.696 \\
\hline 2 & $\mathrm{Ni}$ & 0.00305 \\
\hline 3 & $\mathrm{Cu}$ & 0.00424 \\
\hline 5 & $\mathrm{Ga}$ & 0.00117 \\
\hline 6 & $\mathrm{Ce}$ & 0.0307 \\
\hline 7 & $\mathrm{Ta}$ & 0.0038 \\
\hline 8 & W & 0.136 \\
\hline 9 & $\mathrm{Mg}$ & 3.79 \\
\hline 10 & $\mathrm{Al}$ & 6.105 \\
\hline 11 & $\mathrm{Si}$ & 10.940 \\
\hline 12 & $\mathrm{P}$ & 1.1093 \\
\hline 13 & S & 0.5482 \\
\hline 14 & $\mathrm{Cl}$ & 2.716 \\
\hline 15 & $\mathrm{~K}$ & 10.964 \\
\hline 16 & $\mathrm{Ca}$ & 9.305 \\
\hline 17 & $\mathrm{Ti}$ & 0.2204 \\
\hline 19 & $\mathrm{Cr}$ & 0.00031 \\
\hline 20 & $\mathrm{Mn}$ & 0.05842 \\
\hline 21 & $\mathrm{Ba}$ & 0.1591 \\
\hline 22 & As & 0.00201 \\
\hline 23 & $\mathrm{Br}$ & 0.00198 \\
\hline 24 & $\mathrm{Rb}$ & 0.01462 \\
\hline 25 & $\mathrm{Sr}$ & 1.003 \\
\hline 26 & $\mathrm{Y}$ & 0.001662 \\
\hline 27 & $\mathrm{Zr}$ & 0.0257 \\
\hline 28 & $\mathrm{Nb}$ & 0.001366 \\
\hline 29 & $\mathrm{Sn}$ & 0.057 \\
\hline 30 & $\mathrm{~Pb}$ & 0.00014 \\
\hline
\end{tabular}

\subsection{X-ray diffraction analysis}

XRD result exhibited characteristic peaks of crystalline phases consistent with the major mineral constituents being kaolinite minerals $\left(\mathrm{Al}_{2} \mathrm{Si}_{2} \mathrm{O}_{9}\right)$, Muscovite $\left(\mathrm{Al}_{12} \mathrm{FeSi}_{12} \mathrm{~K}_{4} \mathrm{NaRbH}_{16} \mathrm{O}_{48}\right)$, quartz, $\mathrm{Si}_{3} \mathrm{O}_{6}$ Calcite $\left(\mathrm{Ca}_{6} \mathrm{C}_{6} \mathrm{O}_{18}\right)$ and Halite $\left(\mathrm{Na}_{4} \mathrm{Cl}{ }_{4}\right)$ (Figure 1). The $\mathrm{XRD}$ profile at $2 \theta=5^{\circ}-70^{\circ}$ reveals the nature of the Magnetic sand/Crotalaria pallida/Kaolin catalyst which exhibits well resolved and intense peaks at $27^{\circ}$, followed by $25^{\circ}$ and $12.5^{\circ}$, while less intense peaks were found at $12.4^{\circ}, 20.3^{\circ}, 20.86^{\circ}, 23.16^{\circ}, 24.87^{\circ}, 26.64^{\circ}, 28.74^{\circ}, 29.39^{\circ}, 31.84^{\circ}$, $32.5^{\circ}, 34.9^{\circ}, 35.9^{\circ}, 36.4^{\circ}, 37.69^{\circ}, 38.52^{\circ}, 39.26^{\circ}, 40.60^{\circ}, 41.8^{\circ}, 42.38^{\circ}, 43.24^{\circ}, 45.3^{\circ}, 45.95^{\circ}, 48.63^{\circ}, 50.39^{\circ}, 50.91^{\circ}, 55.02^{\circ}, 57.32^{\circ}, 60.17^{\circ}$, $60.99^{\circ}, 62.41^{\circ}, 64.17^{\circ}, 64.49^{\circ}, 66.46^{\circ}, 68.45^{\circ}, 70.7^{\circ}$ and $73.85^{\circ}$. The main peaks were observed at around $2 \theta=26.64^{\circ}, 39.39^{\circ}, 24.87^{\circ}$ and $12.4^{\circ}$. By investigating the most intense peaks, the crystallite size was calculated from its line broadening and the average crystallite size was gotten to be $75.30 \mathrm{~nm}$.

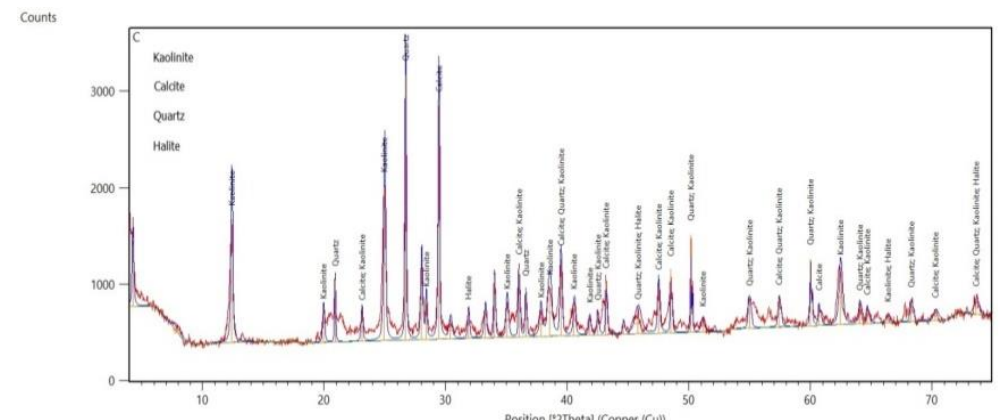

Fig. 2: XRD Spectrum of Magnetic Sand/Crotalaria pallida/Kaolin Catalyst Material.

\section{Conclusion}

A heterogeneous catalyst material has prepared from Magnetic sand and Crotalaria pallida, impregnated with kaolin by a wet impregnation method, and the catalyst material has been characterized and studied for the catalyst properties. This catalyst is being developed for application in the production of biodiesel from seed oils. The findings from the characterization techniques showed that the material possesses large, layered pore structure with small basal spacing which makes it suitable for use as heterogeneous catalysts. The results are in correlation with earlier studies conducted by Liu et. al. (2018), Babajide et. al. (2010), Tukur et al. (2017) and Edeh et. al. (2018). From these findings and the comparison with previous works done by earlier researchers, it can be inferred that the hybrid material of magnetic sand, Crotalaria pallida and kaolin will perform excellently as heterogeneous catalyst for several chemical processes such as transesterification reaction of seed oils. 


\section{Acknowledgement}

This research was hugely supported by Mr. Muhammad Fadlu of the American University of Nigeria, Yola. We are immensely grateful to all our colleagues and group members for the expertise provided that greatly assisted and enhanced this research.

We have to express our profound gratitude to Mrs. Beatrice Penuel for her enormous support and guidance in carrying out this research. Technical support by Mr. Alexander Abel of Modibbo Adama University of Technology, Yola is also highly acknowledged and appreciated.

\section{References}

[1] Prajitha Prabhakaran MK \& Pushpaletha P (2017), Catalyst Preparation, Characterization and Catalytic Activity of Kaolinite Clay from Nileswar, Kerala, International Journal of Applied Chemistry. ISSN 0973-1792 Volume 13, Number 3 (2017) pp. 461-475.

[2] Council for Chemical Research, Vision 2020 Catalysis Report, 1998, Available online: http://www.ccrhq.org/vision/index/roadmaps/catrep.html.

[3] Bartholomew CH \& Farrauto RJ (2005), Fundamentals of Industrial Catalytic Processes, 2nd ed., Wiley-AIChE. https://doi.org/10.1002/9780471730071.

[4] Morbidelli M, Gravriilidis A \& Varma A (2001), Catalyst Design: Optimal Distribution of Catalyst in Pellets, Reactors and Membranes, Cambridge University Press, Cambridge, UK, 2001. https://doi.org/10.1017/CBO9780511721762.

[5] John NA (2011), A history of industrial catalysis, Catalysis Today, Volume 163, Issue 1, (2011) Pages 3-9, ISSN 0920-5861, https://doi.org/10.1016/j.cattod.2009.11.019.

[6] Fechete I, Wang Y, \& Védrine JC (2012), the past, present and future of heterogeneous catalysis. Catalysis Today, 189(1), 227. https://doi.org/10.1016/j.cattod.2012.04.003.

[7] Zaera F (2013), Nanostructured materials for applications in heterogeneous catalysis. Chem. Soc. Rev., 42(7), 27462762. https://doi.org/10.1039/C2CS35261C.

[8] Li Y \& Shen W (2014), Morphology-dependent nanocatalysts: Rod-shaped oxides. Chem. Soc. Rev., 43(5), 15431574. https://doi.org/10.1039/C3CS60296F.

[9] Tanabe, K., 1981. Solid acid and base catalysis. In: Anderson, J.R., Boudart, M. (Eds.), Catalysis Science and Technology. Springer, New York, p. 231. https://doi.org/10.1007/978-3-642-93171-0_5.

[10] Li L, Liu X, Ge Y, Xu R, Rocha J \& Klinowski J (1993), Structural studies of pillared saponite. J Phys Chem, 97, pp. 10389- 10393. https://doi.org/10.1021/j100142a021.

[11] Dass PM, Shalbugau KW, Iji M \& Penuel BL (2020), Synthesis and characterization of heterogeneous catalysts from magnetic sand and kaolin. Journal of Chemistry Letters, 1(3), 139-142.

[12] Eisenmesser EZ (2002), Enzyme Dynamics during Catalysis. Science, 295(5559), 1520-1523. https://doi.org/10.1126/science.1066176.

[13] Liu Y \& Pinnavaia TJ (2004), Metakaolin as a reagent for the assembly of mesoporous aluminosilicates with hexagonal, cubic and wormhole framework structures from proto-faujasitic nanoclusters. Journal of Materials Chemistry, 14(23), 3416. https://doi.org/10.1039/b410337h

[14] Liu J, Yun Z \& Gui X (2018), Ce/kaolin clay as an active catalyst for fatty acid methyl esters production from cottonseed oil in a new integrated apparatus. Brazilian Journal of Chemical Engineering, 35(1), 147-154. https://doi.org/10.1590/0104-6632.20180351s20160504.

[15] Holmes SM, Alomair AA \& Kovo AS (2012), the direct synthesis of pure zeolite-A using "virgin" Kaolin. RSC Advances, 2(30), 11491. https://doi.org/10.1039/c2ra22263a.

[16] Holmes SM, Khoo SH \& Kovo AS (2011), the direct conversion of impure natural kaolin into pure zeolite catalysts. Green Chemistry, 13(5), 1152. https://doi.org/10.1039/c1gc15099e.

[17] Kovo AS, Hernandez O \& Holmes SM (2009), Synthesis and characterization of zeolite Y and ZSM-5 from Nigerian Ahoko Kaolin using a novel, lower temperature, metakaolinization technique. Journal of Materials Chemistry, 19(34), 6207. https://doi.org/10.1039/b907554b.

[18] Belviso C, Cavalcante F, Lettino A \& Fiore S (2013), A and X-type zeolites synthesised from kaolinite at low temperature. Applied Clay Science, 80-81, 162-168. https://doi.org/10.1016/j.clay.2013.02.003.

[19] Shen B, Wang P, Yi Z, Zhang W, Tong X, Liu Y \& Xu C (2009), Synthesis of Zeolite $\beta$ from Kaolin and Its Catalytic Performance For FCC Naphtha Aromatization. Energy \& Fuels, 23(1), 60-64. https://doi.org/10.1021/ef800681e.

[20] Friday, Edeh \& Joel, J.M \& Yelwa, Jibrin \& Barminas, Jeffrey. (2018). Development and characterization of heterogeneous kaolin/ash based catalyst system. Material Science, 16(3), 1-8.

[21] Tukur FJ, Barminas JT, Khan ME \& Abel A (2017), Potential of magnetic sand as catalyst for the heterogeneous transesterification of Luffa (Luffa cylindrica) seed oil to biodiesel. Current Journal of Applied Science and Technology, 21(6), (2017) 1-11 https://doi.org/10.9734/CJAST/2017/30482.

[22] Babajide O, Petrik L, Musyoka N, Amigun B \& Ameer F (2010) Use of coal fly ash as a catalyst in the production of biodiesel. Petroluem \& Coal 52 (4) 261-272, ISSN 1337-7027. 